\title{
Production subsidies and redistribution *
}

\author{
Marina Azzimonti $†$ Eva de Francisco; and Per Krusell ${ }^{\S}$
}

December, 2006

\begin{abstract}
Who gains from stimulating output? We explore a dynamic model with production subsidies where the population is heterogeneous in one dimension: wealth. There are two channels through which production subsidies redistribute resources across the population. First, poorer agents gain from a rise in wages, since - to the extent there is an operative wealth effect in labor supply - they work harder. Second, because a current output boost will raise consumption today relative to the future, thus lowering real interest rates, poor agents gain in relative terms since their income is based less on interest income. We examine optimal redistribution from the perspective of an arbitrary consumer in the population. We show that, if this consumer has commitment at time zero to set all present and future subsidy rates, and for a class of preferences that admits aggregation in wealth, then output stimulation, and hence redistribution, will only occur at time zero; after that, subsidies are zero. A byproduct of our analysis of this environment is a median-voter theorem: with direct voting over subsidy sequences at time zero, the sequence preferred by the median-wealth consumer is the unique outcome. We also study lack of commitment, since interest-rate manipulation is associated with time inconsistency. We analyze this case formally by looking at the Markov-perfect (time-consistent) equilibrium in a game between successive identical decision makers (e.g., the median agent). Here, subsidies persist - they are constant over time - and are more distortionary than under commitment. Moreover, whereas under commitment asset inequality changes initially - in favor of the consumer who decides on policy — it does not under lack of commitment.
\end{abstract}

JEL Classification: E61, E62, H11, H29, H41, O23

Keywords: Commitment, Markov Equilibrium, Time Consistency, Production Subsidies, Aggregation.

\footnotetext{
*We wish to thank Atsushi Oshima for excellent research assistance.

$\dagger$ University of Iowa and Federal Reserve Bank of Richmond. Email: marina-azzimonti@uiowa.edu.

†Towson University. Email: edefrancisco@towson.edu.

§Princeton University. Email: pkrusell@princeton.edu.
} 


\section{Introduction}

Because consumers are not identical, macroeconomic policy may have different impact on different subgroups of the population. In this paper, we focus on consumer heterogeneity in wealth, and we ask how fiscal policy — aimed at stimulating output - influences different consumers. We use a simple dynamic general-equilibrium model with perfect competition where consumers are unrestricted in their borrowing and lending. That is, we study the workhorse "neoclassical" model, used widely in macroeconomics both in the context of real-business-cycle analysis and in monetary economics, extended to admit wealth heterogeneity. Our approach is ask what a consumer with a given position in the wealth distribution would choose were he given the powers to determine the output subsidy. Our setting admits aggregation in wealth, so a consumer with mean wealth holdings would choose to set subsidies to zero at all times: the laissez-faire equilibrium is optimal from the perspective of the "representative consumer". However, any other agents would use the subsidy actively to redistribute resources in their favor. One special case of our setting is one where there is majority voting over subsidy levels, and we analyze this case in some detail.

The economy we study has one consumption good, and this good is produced using labor; the production function is linear in labor and there is no role for physical or any other form of real capital accumulation. The economy is closed, and each period there are two aggregate outcomes of interest: the amount of hours worked (and hence the level of output) and the price of one-period real bonds (and hence the real interest rate between the present and next period). Given this setting, there are two channels through which the stimulation of output through production subsidization will redistribute resources across the population. First, poorer agents gain from a rise in wages, since - to the extent there is an operative wealth effect in labor supply - they work harder. In other words, since output stimulation must raise labor input, it works like a tax on leisure: rich consumers both consume more goods and enjoy more leisure if these goods are normal goods, and thus poor consumers receive a net transfer. Second, everything else equal, a current output boost will raise consumption today relative to consumption in the future. Thus, real interest rates fall, and poor agents again gain in relative terms since interest income is less important for them than for rich agents.

The possibility of "manipulation" of interest rates also leads to time-consistency problems: the equilibrium outcomes differ depending on whether or not there is a commitment device for future policy. The reason is that an output stimulation today raises aggregate consumption, and therefore it raises the interest rate between yesterday and today. This effect will be ignored if the tax rate is chosen today, but it would have been taken into account had the tax choice been made yesterday. The time-inconsistency problem means that, in this economy, whether a designated policymaking agent can commit to a sequence of subsidy rates in advance or is allowed to reoptimize results in different policy sequences. Part of the purpose of the present study is to examine just how commitment makes a difference.

Our findings are quite striking. In short, we point to (i) rather surprising features of the commitment solution, and (ii) a stark qualitative difference between the solutions with and without commitment. As for the first point, suppose that the policymaker is poorer than the consumer with average wealth. Such a policymaker, we show, will then set subsidies so that there is initial output stimulation, and so that asset inequality shrinks (but does not go away). However, after one period, subsidization goes to zero and stays at zero permanently, and the asset distribution remains unchanged. As for the second point, we find that when there is no commitment, the first period is not different: subsidization is permanent, and asset inequality does not change at all over time. 
Our first main finding - that a policymaker, who in a static economy would want to use the subsidy, will only use it for one period, thus leaving the economy undistorted in the "long run" - is reminiscent of the results in Chamley (1986) and Judd (1985). These studies also have a stark finding: that optimal capital taxes in a dynamic economy are zero in the long run. However, our finding appears for entirely different reasons. The essence of the intuition here is based on the fact that, when preferences admit aggregation and there is a wealth effect in labor supply, all that matters for consumer utility is average utility and his relative wealth position, and these two factors are multiplicatively separable. ${ }^{1}$ Moreover, the former is maximized at zero taxes, and the latter entails two counteracting effects of a future subsidy hike. On the one hand, the subsidy hike implies direct redistribution toward a policymaker who is poor in relative terms. On the other hand, by raising output at that date, it lowers marginal utility and thus the present value of any labor income at that future date. Given our preference assumptions, we can show that these two effects exactly cancel for any future date. In contrast, at time zero, there is a net gain from subsidization since there is no counteracting discounting effect. Though we know that our finding does not hold generally outside the preference class we consider, this class contains most, if not all, of the specifications in the applied (quantitative) macroeconomic literature.

As a byproduct of our analysis of the commitment case, we show that under our preference assumptions, one can show that a median-voter theorem applies: if consumers vote directly over subsidy sequences at time zero, in pairwise contests, then there is a unique winning sequence, namely, that which is the optimal choice by the consumer with median wealth. It is difficult to obtain analytical characterization of the set of voting equilibria in dynamic models, and the present result points to a way forward that may allow some generalization, at least under commitment: the use of preferences that admit aggregation. ${ }^{2}$

We analyze the case without commitment using a Markov-perfect equilibrium notion, as in the politico-economic equilibria studied in Krusell and Ríos-Rull (1999). ${ }^{3}$ That is, we consider a policymaker's choice as the outcome of a dynamic game where the equilibrium notion demands that subsidies in any period are a function of the payoff-relevant state and nothing else. Given that there is no physical capital and that the environment is stationary, this payoff-relevant state is the distribution of asset holdings. However, this distribution does not matter per segiven aggregation-but only through its effect on the policy choice. Therefore, the relevant state is precisely the asset holding of the policymaker, and this variable only. We are not able to prove existence of a Markov-perfect equilibrium globally for our model but, in the special case of logarithmic utility, and using the first-order condition, we discuss local existence around the point where the policymaker's assets equal mean assets. One can also see that, if an equilibrium exists globally and is smooth, then it gives higher first-period subsidies than those found under commitment. Thus, a lack of commitment leads to uniformly higher distortions: not only do subsidies remain positive from period two and on, but they are also higher in the first period.

Mathematically, the functional first-order condition is different than in standard optimal control theory problems since we are studying a dynamic game without commitment: the

\footnotetext{
${ }^{1}$ It is possible to have aggregation in wealth also when there is no wealth effect in labor supply, based on preferences of the sort employed by Greenwood, Hercowitz, and Huffman (1988). We cover this case as well, and also find zero taxes from the second period and on. The intuition for the result here is somewhat different, but shares the essential features of the case with a wealth effect. Finally, there are two other cases, exponential and quadratic utility, that also admit aggregation, but we have not considered these cases.

${ }^{2}$ For another example, see Roberts (1977).

${ }^{3}$ See Maskin and Tirole (2001) for a general discussion of the equilibrium concept.
} 
median voter at a point in time cannot bind the hands of future median voters, whether the latter are different individuals or not. Prior analysis focusing on first-order conditions in similar contexts includes the work on individual saving under time-inconsistent preferences, where reminiscent first-order conditions have been derived (so-called "generalized Euler equations"; see Laibson [1997]), and some recent work on dynamic public finance (e.g., see Klein, Krusell, and Ríos-Rull [2005] or Azzimonti, de Francisco and Krusell [2006]). It turns out that the numerical solution of this functional equation is challenging as well; we illustrate this fact in the paper in a final computational section.

Motivation for our work can be found in various strands of the literature on the effects of policy on inequality and on policy choice. First, aside from a rather large literature on the equity perspective on taxation, which does not take general-equilibrium effects of interest rates into account (see, e.g., Atkinson [1971]), there are rather few studies which look at the effects of proportional taxes on the distribution of consumer utility (and the associated choices and equilibrium aggregates). Most of these studies, moreover, focus on capital income taxation; for examples of quantitative studies, see Garcia-Milà, Marcet, and Ventura (2001) and Altig et al. (2001), and for studies that rely on qualitative investigation see Correia (1999a,b). Correia's work is particularly close to ours, since it relies on the same kind of preference assumptions. It also makes intensive use, as in the present paper, of "initial asset inequality" and complete markets as a determinant of inequality in consumption and other individual outcomes. This is a very convenient vehicle for analyzing inequality, but it is arguably not the best model of the ultimate origins of inequality; Huggett (1993) and Aiyagari (1994) are examples of settings which at least seem more descriptively accurate as models of the evolution of individuals' wealth levels. Our conjecture, however, is that the results in the present paper are not far from those which would obtain in such, more realistic, settings. ${ }^{4}$

Second, our paper is closely related to Lucas and Stokey (1983), which studies tax smoothing and government debt policy; they point to the interest-rate manipulation mechanism, and to the time inconsistency of commitment plans in that context. Our setting is very similar, but for us the net asset positions of interest is between different individuals, instead of between the representative agent and the government as in Lucas and Stokey's work. For this reason, our commitment equilibrium is easier to characterize; in fact, we believe our setting may be the simplest one available for discussing the idea of interest-rate manipulation and its consequences.

Third, a set of papers discussing endogenous policy can be found in the earlier politicaleconomy literature. Meltzer and Richard (1981) study a static model of the sort analyzed here but where heterogeneity appears through labor productivity: some agents are more productive, and earn more, than others. A dynamic version of their model without capital would allow asset accumulation on the individual level, and it would allow interest-rate manipulation. However, this manipulation would only have a role to play if agents had different initial asset positionsotherwise, the dynamic Meltzer-Richard model would merely be a mechanical repetition of the static one. Thus, what we study here is the most stripped-down version of their economy with asset differences: all the focus is on redistribution due to the wealth differences, and interest-rate manipulation is central. It would seem straightforward to reintroduce productivity differences into the model, which obviously would be a force toward taxation, not subsidization, of labor (assuming, as data suggest, that median labor productivity is below mean labor productivity). The present work also relates to Krusell and Ríos-Rull (1999), who study a

\footnotetext{
${ }^{4}$ This conjecture is based on the near-aggregation that applies in such models for a wide range of parameter values; see Krusell and Smith (1998, 2006).
} 
dynamic Meltzer-Richard model with capital. In that model, there is a proportional tax on both labor and capital, and the focus is mainly quantitative. The present paper contributes further analytical and computational insights focusing on a mechanism that is present in that paper and that should be broadly relevant in this literature: interest-rate manipulation. I.e., when interest rates are endogenous and have differential impact on consumers of different wealth levels, the political decisions over interest rates will involve redistribution and will have features of time inconsistency. Finally, our median-voter result under commitment is related to Bassetto and Benhabib (2006), who study a capital taxation economy with a similar preference structure; they use similar reasoning to prove their median-voter result.

The paper is organized as follows. Section 2 describes the basic economic model for exogenous policy. This section demonstrates aggregation and characterizes equilibrium prices (interest rates) and quantities as a function of the sequence of subsidies chosen by the government. Section 3 studies how an arbitrary agent chooses a subsidy sequence to maximize his equilibrium utility under commitment. As a special case, this section demonstrates a median-voter theorem and characterizes the median-voter equilibrium. Section 4 then defines and studies Markov-perfect equilibria when there is no commitment. Section 5 concludes the paper.

\section{The model}

In this section, we describe the economic model for exogenous policy: we define the sequential competitive equilibrium for a given sequence of subsidies. We then specialize preferences to admit aggregation and characterize the equilibrium in this case. This analysis will form the building block for the later analysis of the endogenous choice of policy.

In this infinite-horizon economy, time is discrete and there is no uncertainty. Agents value consumption, $c$, and leisure, $l$, and preferences are the same for everyone:

$$
\sum_{t=0}^{\infty} \beta^{t} u\left(c_{t}, l_{t}\right) .
$$

Agents can trade one-period bonds, each promising one unit of consumption next period. The heterogeneity within the population enters only through differences in consumers' initial asset holdings. We will assume that the number of "types" is finite with measure $\mu_{i}$ for type $i \in\{1,2, \ldots, I\}$. The population size is normalized to one: $\sum_{i=1}^{I} \mu_{i}=1$.

Production takes place according to a stationary production function which depends linearly on labor: $Y=N$ (we use capital letters to denote aggregates). Output is used for consumption, and there is no government consumption or investment. We also abstract from capital entirely. The level of asset holdings of individual $i$ is denoted by $a_{i}$, which is in zero net supply in equilibrium. Thus, neither storage nor trade with other countries is possible.

Each consumer is endowed with one unit of time, so that $l_{i}+n_{i}=1$ for all $i$. We will make assumptions on primitives so that agents' decision problems are strictly concave; hence, all agents of the same type will make the same decisions and we can also write $L_{i}+N_{i}=1$, where $L_{i}$ and $N_{i}$ reflect common decisions regarding leisure and labor of all agents of type $i$. The aggregate labor input is thus $N=\sum_{i=1}^{I} \mu_{i} N_{i}$. 


\subsection{Sequential competitive equilibrium given subsidies}

In a decentralized economy, consumers buy consumption goods at each point in time and sell their labor services to firms under perfect competition. There are two relevant prices determined in equilibrium: the price of one-period bonds, denoted by $q$, and the wage rate $w$, both measured in terms of consumption goods in the same period. In addition, we now consider a government that subsidizes production at a proportional rate $\tau_{t}$ in period $t$. The revenues are collected through equal lump-sum taxes $T_{t}$ under a balanced budget. Thus, a typical consumer $i$ 's budget constraint in period $t$ reads

$$
c_{t i}+q_{t} a_{i t+1}=a_{i t}+w_{t}\left(1-l_{i t}\right)-T_{t},
$$

where $w_{t}=1+\tau_{t}$ in equilibrium, since the subsidy is translated into the wage rate when labor markets are competitive and firms operate under zero profits. In equilibrium, consumers' holdings of assets have to add up to zero: $\sum_{i=1}^{I} \mu_{i} A_{i t}=0$, where $A_{i t}$ denotes the total holdings of agents of type $i$. Consumer heterogeneity thus originates in $a_{i 0} \neq a_{j 0}$ for all $i \neq j$. We define a competitive equilibrium for a given sequence of government policy as follows:

Definition 1 Given a sequence of subsidies $\left\{\tau_{t}\right\}_{t=0}^{\infty}$, a competitive equilibrium is a sequence of prices $\left\{w_{t}, q_{t}\right\}_{t=0}^{\infty}$ together with a sequence of allocations $\left\{N_{t},\left\{C_{i t}, A_{i t+1}, L_{i t}\right\}_{i=1}^{I}, T_{t}\right\}_{t=0}^{\infty}$ satisfying the following conditions.

1. For all $i,\left\{C_{i t}, A_{i t+1}, L_{i t}\right\}_{t=0}^{\infty}$ solves

$$
\max _{\left\{c_{t}, a_{t+1}, l_{t}\right\}_{t=0}^{\infty}} \sum_{t=0}^{\infty} \beta^{t} u\left(c_{t}, l_{t}\right) .
$$

subject to

$$
c_{t}+q_{t} a_{t+1}=a_{t}+w_{t}\left(1-l_{t}\right)-T_{t} .
$$

for all $t$, with $a_{0}=A_{i 0}$, and subject to a no-Ponzi scheme condition:

$$
\lim _{t \rightarrow \infty} a_{t} \Pi_{k=0}^{t-1} q_{k}=0 .
$$

2. For all $t, w_{t}=1+\tau_{t}$.

3. For all $t, N_{t}=\sum_{i=1}^{I} \mu_{i}\left(1-L_{i t}\right)$.

4. For all $t, \sum_{i=1}^{I} \mu_{i} A_{i t}=0$.

5. For all $t, T_{t}=\tau_{t} N_{t}$.

An agent with wealth $A_{i 0}$ will choose to accumulate assets and consume leisure so that

$$
u_{c}\left(c_{i t}, l_{i t}\right) w_{t}=u_{l}\left(c_{i t}, l_{i t}\right)
$$

and

$$
q_{t} u_{c}\left(c_{i t}, l_{i t}\right)=\beta u_{c}\left(c_{i t+1}, l_{i t+1}\right) .
$$

Together with the budget constraints and a transversality condition, these conditions are sufficient for finding optimal consumer choices. In order to find an equilibrium, we need to aggregate across consumers and find the equilibrium bond prices that clear asset markets. To accomplish this, we will make additional assumptions on preferences. 


\subsection{Aggregation}

Our additional assumption on utility functions are made in order to deliver aggregation.

Assumption 1: Let the instantaneous utility be

$$
u\left(c_{i t}, l_{i t}\right)=\frac{\left[g\left(c_{i t}-\bar{c}, l_{i t}-\bar{l}\right)\right]^{1-\sigma}}{1-\sigma},
$$

where $g$ is homogeneous of degree one in both arguments and $\bar{c}$ and $\bar{l}$ are constants common to all agents.

The constant $\bar{c}$ can be interpreted as a subsistence level of consumption and $\bar{l}$ as a minimum amount of leisure or non-working time that agents enjoy. Under this assumption, the first-order conditions take a particularly simple form. As a result, the competitive equilibrium aggregates and prices are independent of the distribution of asset holdings. ${ }^{5}$ We also consider another preference class which admits aggregation, namely one where there are no wealth effects on labor supply; see section 3.2 below.

To simplify notation, it is useful to work with adjusted consumption and leisure, which we define as $\hat{c}_{i t}=c_{i t}-\bar{c}$ and $\hat{l}_{i t}=l_{i t}-\bar{l}$. The budget constraint becomes

$$
\hat{c}_{i t}=a_{t}+\left(1+\tau_{t}\right)\left(1-\hat{l}_{i t}\right)-T_{t}-q_{t} a_{t+1}-\bar{\gamma}_{t},
$$

where $\bar{\gamma}_{t}=\bar{c}+\bar{l}\left(1+\tau_{t}\right)$ represents total fixed costs of minimum consumption and leisure spending plus the opportunity cost in terms of foregone subsidies of non-working time, $\bar{l}_{t}$.

From agent $i$ 's leisure choice, we see that all agents choose the same ratio of (adjusted) leisure to (adjusted) consumption: $\frac{\hat{l}_{i t}}{\hat{c}_{i t}}=z_{t}$. This ratio satisfies

$$
\frac{g_{2}\left(1, z_{t}\right)}{g_{1}\left(1, z_{t}\right)}=1+\tau_{t}
$$

thus, it is just a function of the current subsidy rate.

The same agent chooses asset holdings so that

$$
\frac{\hat{c}_{i t+1}}{\hat{c}_{i t}}=\left(\frac{\beta}{q_{t} \epsilon_{t}}\right)^{\frac{1}{\sigma}},
$$

where $\epsilon_{t}=\frac{g_{1}\left(1, z_{t}\right)}{g_{1}\left(1, z_{t+1}\right)}\left[\frac{g\left(1, z_{t+1}\right)}{g\left(1, z_{t}\right)}\right]^{\sigma}$. Thus, the growth rate of adjusted consumption is independent of idiosyncratic characteristics. Finally, individual asset holdings must evolve according to

$$
a_{i t+1}=\left(a_{i t}+w_{t}\left(1-\hat{l}_{i t}\right)-T_{t}-\hat{c}_{i t}-\bar{\gamma}_{t}\right) / q_{t}
$$

For completeness, we state

Proposition 1: Under Assumption 1 the competitive equilibrium exhibits aggregation.

Though the result is well known, we demonstrate it by a guess-and-verify strategy, since the guess plays a role in the further characterization of equilibrium. By our guess, aggregate quantities and prices can be found by solving the maximization problem of a representative

\footnotetext{
${ }^{5}$ For a discussion of aggregation in an economy with capital see, e.g., Krusell and Ríos-Rull (1999) and Azzimonti, de Francisco, and Krusell (2006).
} 
agent holding average wealth. We will thus refer to him as the mean agent. In other words, his asset holdings are zero, since $\sum_{i=1}^{I} \mu_{i} A_{i t}=0$. The mean agent would consume goods and leisure according to

$$
\hat{L}_{t}=z_{t} \hat{C}_{t}
$$

where the value of $z_{t}$ is implicitly defined by equation 1 , and

$$
\hat{C}_{t}+\left(1+\tau_{t}\right) \hat{L}_{t}+\bar{\gamma}_{t}=1+\tau_{t}-T_{t} \equiv f_{t} .
$$

Here, we have written resources as the total subsidized value of time minus taxes, which we denote $f_{t}$; on the expenditure side, we have expenditures on consumption and leisure. The function $f$ describes the economically relevant current income of any agent in the economysince it is based on the total amount of time, not hours actually worked, and all agents have the same time endowment and productivity — as a function of the current subsidy rate.

In equilibrium $T_{t}=\tau_{t}\left(1-L_{t}\right)$. Therefore,

$$
\hat{C}_{t}=\frac{1-\bar{c}-\bar{l}}{1+z_{t}} .
$$

We see that the consumption and leisure allocations of the mean agent depend only on current subsidies; this result really follows since the assets of the representative agent must be zero at all points in time (due to aggregation), and thus the representative-agent economy reduces to a static one. So if the subsidy rates were constant over time, aggregates and prices would also be constant. However, if they are not, there will be changes in the asset distribution over time, as we will see below, even though mean assets remain at zero.

The first-order condition of an agent with average wealth implies

$$
\frac{\hat{C}_{t+1}}{\hat{C}_{t}}=\left[\frac{\beta}{q_{t} \epsilon_{t}}\right]^{1 / \sigma}
$$

so the growth rate of adjusted consumption is identical to that chosen by an arbitrary agent in this economy. It is immediate, now, that a summing up of leisure, consumption, and asset choices of individual agents delivers the expressions for averages given above. Using the definition of consumption of the mean agent, we conclude that the price of bonds in equilibrium must be

$$
q_{t}=\beta\left(\frac{1+z_{t+1}}{1+z_{t}}\right)^{\sigma} \frac{1}{\epsilon_{t}} .
$$

Thus, the interest rate equals the discount rate if and only if subsidies are constant over time.

Aggregation allows us to characterize a competitive equilibrium by stating agents' consumption and leisure decisions as proportional to mean consumption and mean leisure. The proportion is given by their share of after-tax (potential) lifetime income in present value terms. We now proceed to provide the appropriate expressions.

We can insert the equilibrium price of bonds, $q_{t}$, into equation (2). The resulting growth rate of consumption depends only on current and next period's subsidies:

$$
\frac{\hat{c}_{i t+1}}{\hat{c}_{i t}}=\frac{1+z_{t}}{1+z_{t+1}}=\frac{\hat{C}_{t+1}}{\hat{C}_{t}},
$$

with

$$
\hat{c}_{i t}=\frac{f_{t}+a_{i t}-q_{t} a_{i t+1}-\bar{\gamma}_{t}}{1+\left(1+\tau_{t}\right) z_{t}} .
$$


The present-value budget constraint of an agent with initial asset holdings $a_{i 0}$ is given by

$$
\underbrace{\sum_{t=0}^{\infty} \prod_{k=0}^{t} q_{k-1}\left\{\hat{c}_{i t}\left[1+\left(1+\tau_{t}\right) z_{t}\right]+\bar{\gamma}_{t}\right\}}_{\text {PV adjusted consumption }}=\underbrace{a_{i 0}+\sum_{t=0}^{\infty} \prod_{k=0}^{t} q_{k-1} f_{t}}_{\text {PV income }}
$$

with $q_{-1} \equiv 1$. We can further simplify this expression and, using equation (4) and the fact that $\hat{C}_{t}=\frac{f_{t}-\bar{\gamma}_{t}}{1+\left(1+\tau_{t}\right) z_{t}}$, solve for initial consumption

$$
\hat{c}_{i 0}=\hat{C}_{0}\left[1+\frac{a_{i 0}}{E(\tau)}\right]
$$

where $\tau$ denotes the entire sequence of subsidies, i.e., $\tau \equiv\left\{\tau_{t}\right\}_{t=0}^{\infty}$, and

$$
E(\tau)=\sum_{t=0}^{\infty} \prod_{k=0}^{t} q_{k-1}\left[f_{t}-\bar{\gamma}_{t}\right]
$$

is the present value of net-of-tax time endowments and transfers received from the government, but adjusted by the cost of subsistence consumption and leisure. It is also the lifetime disposable income of the mean agent in present value terms. An arbitrary agent is thus consuming a proportion of mean consumption. This proportion is given by the share of the consumer's present-value wealth net of taxes, subsidies obtained from adjusted time endowment, and initial assets,

$$
\lambda_{i}(\tau) \equiv \frac{E(\tau)+a_{i 0}}{E(\tau)}=1+\frac{a_{i 0}}{E(\tau)} .
$$

We thus find that

$$
\hat{c}_{i t}=\hat{C}_{t} \lambda_{i}(\tau) \text { and } \hat{l}_{i t}=\hat{L}_{t} \lambda_{i}(\tau) .
$$

Our equilibrium exists if $\lambda_{i}(\tau) \geq 0$ for all $i$, i.e., if all agents can afford positive consumption and leisure, which depends on the given sequence of subsidies. This can be viewed as a restriction on inequality, given a policy sequence, or as a restriction on sequences of taxes and subsidies, given an asset distribution. For some asset distributions, however, no sequence of subsidies admit positive consumption, because even the use of infinite subsidies to labor income is not enough to generate positive consumption for the poorest. However, such initial asset distributions do not make sense, since they could never have been chosen at earlier dates.

Summarizing the information above, we can characterize the competitive equilibrium in terms of the allocations chosen by the mean agent. The following proposition summarizes our result.

Proposition 2: Under Assumption 1 and a given sequence of subsidies $\tau=\left\{\tau_{t}\right\}_{t=0}^{\infty}$ satisfying $\lambda_{i}(\tau) \geq 0$ for all $i$, there exists a competitive equilibrium, and it is given as follows.

1. Taxes are $T_{t}=\tau_{t}\left(1-\hat{L}_{t}-\bar{l}\right)$.

2. The bond price is

$$
q_{t}=\beta\left(\frac{1+z_{t+1}}{1+z_{t}}\right)^{\sigma} \frac{1}{\epsilon_{t}} .
$$


3. Consumption and leisure allocations satisfy

$$
\begin{gathered}
\hat{c}_{i t}=\hat{C}_{t} \lambda_{i}(\tau) \text { and } \hat{l}_{i t}=\hat{L}_{t} \lambda_{i}(\tau) \text { where } \\
\lambda_{i}(\tau)=\left[1+\frac{a_{i 0}}{E(\tau)}\right],
\end{gathered}
$$

with $E(\tau)$ given by equation (5) above. Per-capita values are

$$
\hat{C}_{t}=\frac{1-\bar{c}-\bar{l}}{1+z_{t}}
$$

and

$$
\hat{L}_{t}=z_{t} \frac{1-\bar{c}-\bar{l}}{1+z_{t}}
$$

4. Assets follow

$$
a_{i t+1}=\left(a_{i t}-\left[\lambda_{i}(\tau)-1\right]\left(f_{t}-\bar{\gamma}_{t}\right)\right) \frac{1}{q_{t}}
$$

\section{Redistribution using fiscal policy, commitment}

The equilibrium characterization above implies that any agent who is poorer than average (i.e., with $\left.a_{i 0}<0\right)$ will enjoy less consumption and leisure than the mean agent: $\lambda_{i}(\tau)<1$. While this share is constant for a given stream of subsidies $\tau$, alternative sequences of subsidies will modify it. It is now clear where the core of the disagreement regarding policy in this economy lies: agents realize that they can modify their share of average consumption and leisure through $\tau$. There is a cost associated to this manipulation, and it is given by the distortions introduced on the labor decision. That is, alternative policies have different implications for $\hat{C}_{t}$ or $\hat{L}_{t}$, and we know that zero subsidies is the best choice for the mean agent, thus leaving $g_{1}\left(1, z_{t}\right)=g_{2}\left(1, z_{t}\right)$ - so that the ratio of leisure to consumption is constant over time - as his undistorted, best outcome. If an agent with non-zero initial assets could decide, however, it is clear that a non-zero sequence of subsidies would be chosen, since there is a first-order marginal benefit from departing from zero subsidies - the change in the share of resources - and only a second-order loss.

In order to determine the policy sequence preferred by an agent with an initial asset position $a_{i 0}$, it is useful to derive its indirect lifetime utility, where optimal choices of consumption and leisure have been substituted in. It is easy to verify that it is given by

$$
V_{i 0}(\tau)=\lambda_{i}(\tau)^{1-\sigma} V_{0}(\tau),
$$

where $V_{0}(\tau)$ is the utility of the agent with average wealth,

$$
V_{0}(\tau)=\sum_{t=0}^{\infty} \beta^{t} \frac{\left[g\left(\hat{C}_{t}, \hat{L}_{t}\right)\right]^{1-\sigma}}{1-\sigma} .
$$

What is important to note here, for the purpose of characterization, is that $\lambda_{i}(\tau)$ is linear in the only element of heterogeneity in the model: in $a_{i 0}$. 


\subsection{Characterization}

We now proceed to show that if policy was chosen by an agent with asset holdings $a_{i 0}$, under the preference specification adopted and assuming that the agent is completely selfish, subsidies would be zero from period 1 and on, but positive in period 0 if and only if $a_{i 0}<0$.

The key step in the proof is the demonstration that, under our preference specification, $E(\tau)$ can be written as a product of a function only of period-0 subsidies, $\Omega\left(\tau_{0}\right)$, and the present-value utility of the mean agent:

Lemma 1: $E(\tau)=\Omega\left(\tau_{0}\right) V_{0}(\tau)$, with $\Omega\left(\tau_{0}\right) \equiv(1-\sigma) g\left(\hat{C}_{0}, \hat{L}_{0}\right)^{\sigma} g_{1}\left(\hat{C}_{0}, \hat{L}_{0}\right)^{-1}$.

The proof is contained in Appendix 6.1.

Thus, we conclude that the utility of agent $i$ can be written as

$$
V_{i 0}(\tau)=\left[1+\frac{a_{i 0}}{\Omega\left(\tau_{0}\right) V_{0}(\tau)}\right]^{1-\sigma} V_{0}(\tau)
$$

Suppose that agent $i$ could choose the whole sequence of taxes, and had access to a commitment technology. The resulting equilibrium allocation is characterized below.

Proposition 4: Assume that $\sigma \leq 1$. When the policymaker is of type $i$ and chooses $\tau$ to maximize his equilibrium utility, we obtain (assuming, for illustration, that $a_{i 0}<0$ ):

1. For all $t>0, \tau_{t}=0$.

2. $\tau_{0}>0$.

3. $q_{0}>\beta$ and $q_{t}=\beta$ for all $t>0$.

4. For all $i$ such that $a_{i 0}<0, a_{i 0}<a_{i 1}=a_{i 2}=\cdots<0$ and for all $i$ such that $a_{i 0}>0$, $a_{i 0}>a_{i 1}=a_{i 2}=\cdots>0$.

The proof of the first two parts of the proposition is contained in Appendix 6.2. In brief, the proof of the first part involves a straightforward implication of the lemma above, namely, that the first-order condition with respect to $\tau_{t}$ is zero at $\tau_{t}=0$, since $\tau_{t}$ for $t>0$ only appears through $V_{0}(\tau)$, which we know is maximized at zero subsidies; it also involves the verification of a second-order condition. The second-order condition necessitates restricting $\sigma$ from being too large relative to the policymaker's initial debt position; values of $\sigma$ above one can thus be admitted as well, so long as $a_{i 0}$ is above a certain lower bound. The proof of the second part is straightforward. The third and fourth parts of the proposition are immediate implications of the first two parts, together with the earlier characterization of equilibrium prices and quantities for given subsidy sequences.

The result that subsidies are zero in the long run (and even from the second period and on) is surprising, in particular bearing in mind that the policymaker is non-benevolent: he does not put any weight on other agent's preferences (i.e., he chooses the sequence $\tau$ so as to maximize his own utility). One might think that the redistribution generated by subsidies to labor should not just take place at time zero: that at least a minor amount of redistribution in the future would be better than none. The proposition proves this intuition wrong. Zero taxes in the long run is also reminiscent of the findings of Chamley (1986) and Judd (1985). Here, though he is not facing an optimal capital taxation problem, agent $i$ does have an accumulation problem, 
and the subsidy sequence influences the return on savings as well as a period income function, $f_{t}$, similarly to what would occur in the Chamley-Judd settings. We do find that savings are undistorted in the long run, but this outcome would result for any constant subsidy on labor income, whether positive, zero, or negative. The fact that we find that subsidies on labor income will be exactly zero, thus, is what is different and surprising. Thus, though similar on the surface, the result here and the Chamley-Judd finding are not really connected.

The intuition behind the result is instead based on the fact that two opposing forces cancel, as shown in the following corollary of Lemma 1.

Corollary: For all $t>0$, an increase in the subsidy at period $t$ away from the commitment solution triggers ${ }^{6}$

1. a percentage increase in the price of bonds at period $t$ equal to the percentage decrease in the price of period $t-1$ bonds

$$
\frac{d q_{t} / d \tau_{t}}{q_{t}}=-\frac{d q_{t-1} / d \tau_{t}}{q_{t-1}} \geq 0 \text { and }
$$

2. a percentage increase in the adjusted net-of-taxes value of time endowments equivalent to the percentage decrease in $q_{t-1}$

$$
\frac{d\left(f_{t}-\bar{\gamma}_{t}\right) / d \tau_{t}}{f_{t}-\bar{\gamma}_{t}}=-\frac{d q_{t-1} / d \tau_{t}}{q_{t-1}} \geq 0
$$

The proof of the corollary is straightforward using the equations in Appendix 6.1.

On the one hand, output stimulation at time 100 financed by an equal per-capita lumpsum tax makes a poorer agent better off: due to his labor supply being higher, such a policy amounts to a net redistribution in his favor. On the other hand, output stimulation at time 100 lowers the present value of any income in period 100: it raises consumption at that date relative to earlier dates, which makes $q_{99}$ fall. If no other subsidy is changed, then the stationarity of the economy and the absence of capital means that no prior bond price will change, that $q_{100}$ will rise by the same percentage amount that $q_{99}$ falls, and that subsequent bond prices will not change. This in turn means that only the change in the period-100 income and how it is discounted will matter: no net redistribution will occur in other periods, and the change in discounting will only influence period-100 income. In particular, since the subsidy increase means that all period-100 income is now discounted more heavily, there will be a loss for the poor agents since the relative weight of their initial debt in total present-value income will increase: their $\lambda_{i}$ falls. The particular preferences we consider imply that the discounting effect exactly cancels with the net redistribution effect. The cancelation, in turn, derives from the fact that the change in the marginal utility of the period- $t$ consumption-leisure composite is key for both the value of additional income in that period and for the change in the bond price. The preferences also imply that any disagreement between agents can be summarized in how their total wealth shares - their $\lambda \mathrm{s}$ - change; the multiplicative expression in utility above summarizes this claim. Finally, just note that in period zero, only the direct redistribution effect is present, since there is no discounting of period-zero income.

\footnotetext{
${ }^{6}$ The derivative is

$$
\frac{d q_{t}}{d \tau_{t}}=\frac{d z_{t}}{d \tau_{t}} q_{t}\left[\frac{\sigma \tau_{t} g_{1}\left(1, z_{t}\right)}{\left(1+z_{t}\right) g\left(1, z_{t}\right)}-\frac{g_{12}\left(1, z_{t}\right)}{g_{1}\left(1, z_{t}\right)}\right] \geq 0
$$
}

around $\tau_{t}=0$ since $\frac{d z_{t}}{d \tau_{t}}<0$ by implicit differentiation of equation 1 . 


\subsection{Preferences with no wealth effects}

We now look at another case of interest, namely, one where there is no wealth effect on labor supply. So suppose that $g$ instead takes another particular form:

$$
g\left(c_{i t}, l_{i t}\right)=c_{i t}-\chi\left(1-l_{i t}\right)^{\phi} .
$$

It is easy to show that for this preference specification, individual labor supply is independent of wealth, and therefore, that all agents work the same amount of hours. After some manipulation of the first-order conditions of agent $i$, one can show that

$$
n_{i t}=N_{t}=\left(\frac{1+\tau_{t}}{\chi \phi}\right)^{\frac{\phi}{\phi-1}}
$$

and

$$
q_{t}=\beta \frac{\hat{C}_{t+1}}{\hat{C}_{t}},
$$

where $\hat{C}_{t}=\left(1-\chi N_{t}^{\phi-1}\right) N_{t}$.

If agent $i$ 's wealth differs from average wealth, his consumption will also be different from average wealth:

$$
\hat{c}_{i t}=\lambda_{i}(\tau) \hat{C}_{t},
$$

where now

$$
\lambda_{i}(\tau)=1+\frac{a_{i 0}}{\hat{C}_{0}^{-\sigma} V_{0}(\tau)} .
$$

The proof that subsidies are zero from the second period on, but positive in the first period if agent $i$ is poorer than average, is parallel to that described in the previous section. In terms of intuition, since all agents have the same labor supply, there is no direct redistribution among agents in this economy. However, the indirect effect through the interest-rate manipulation is still present, and we find that in the first period, a policymaker poorer than average would choose a positive subsidy to take advantage of the fall in the interest rate caused by this policy. For all subsequent periods, since any change in the subsidy rate has zero net redistribution effects, and since the discounting effect will not influence $\lambda$ either in this case, it is optimal to choose zero subsidies.

\subsection{Majority voting: a median-voter theorem}

The previous characterization presumed that one particular agent, $i$, had the absolute power to choose the whole sequence of policy at time zero. It is interesting to contrast this dictatorial regime to the sequence of taxes that would arise under a voting mechanism.

In this section, we will assume that voting takes place at the beginning of time, and that the policy-setting power has a commitment technology at that point: it can fix a policy sequence for all time. We assume that political competition takes place in the form of direct votes over subsidy sequences, and we assume majority voting.

Definition 2: A majority-voting equilibrium (MVE) is a sequence of subsidies that cannot be beaten in a pairwise voting contest by any other sequence.

A sequence of subsidies is a high-dimensional object and it is thus far from obvious that this definition has content in our economy - it is well known that the existence of an MVE cannot 
be guaranteed except under special circumstances. Here, fortunately, the same assumption on preferences that admits aggregation will allow us to show existence of a majority-voting equilibrium: we will provide a median-voter theorem.

Let $\tau^{*}$ be our candidate majority-voting equilibrium. Then it must be the case that this policy is preferred by at least $50 \%$ of the population to any other policy. We show below that the equilibrium sequence of subsidies is that preferred by the agent with median wealth, i.e., the median agent.

We denote the wealth of the median agent by $a_{*}$. Similarly, his preferred sequence of subsidies is denoted $\tau^{*}$. Thus,

$$
\left(1+\frac{a_{*}}{E\left(\tau^{*}\right)}\right)^{1-\sigma} V_{0}\left(\tau^{*}\right) \geq\left(1+\frac{a_{*}}{E(\tau)}\right)^{1-\sigma} V_{0}(\tau)
$$

for all feasible $\tau$, i.e., for all $\tau$ such that $\lambda_{i}(\tau) \geq 0$ for all $i$.

We now state our median-voter theorem.

Proposition 3: $\tau^{*}$ is a majority-voting equilibrium.

The proof is straightforward, but perhaps instructive. For any alternative feasible $\tau$, we know that

$$
\left(1+\frac{a_{*}}{E\left(\tau^{*}\right)}\right)^{1-\sigma} V_{0}\left(\tau^{*}\right) \geq\left(1+\frac{a_{*}}{E(\tau)}\right)^{1-\sigma} V_{0}(\tau) .
$$

This implies, using simple manipulations, that either

$$
a_{*} \geq \frac{\left(\frac{V_{0}(\tau)}{V_{0}\left(\tau^{*}\right)}\right)^{\frac{1}{1-\sigma}}-1}{\frac{1}{E\left(\tau^{*}\right)}-\frac{1}{E(\tau)}\left(\frac{V_{0}(\tau)}{V_{0}\left(\tau^{*}\right)}\right)^{\frac{1}{1-\sigma}}}
$$

or

$$
a_{*} \leq \frac{\left(\frac{V_{0}(\tau)}{V_{0}\left(\tau^{*}\right)}\right)^{\frac{1}{1-\sigma}}-1}{\frac{1}{E\left(\tau^{*}\right)}-\frac{1}{E(\tau)}\left(\frac{V_{0}(\tau)}{V_{0}\left(\tau^{*}\right)}\right)^{\frac{1}{1-\sigma}}},
$$

depending on the signs of the numerators and denominators in these expressions. Therefore, since half of the population has $a_{i 0} \geq a_{*}$ and the other half, $a_{i 0} \leq a_{*}$, working in reverse, it must be that for half of the population, there is agreement with the choice of the median agent: for more than half the population, their $a_{i 0}$ is such that

$$
\left(1+\frac{a_{i 0}}{E\left(\tau^{*}\right)}\right)^{1-\sigma} V_{0}\left(\tau^{*}\right) \geq\left(1+\frac{a_{i 0}}{E(\tau)}\right)^{1-\sigma} V_{0}(\tau) .
$$

Having established a median-voter theorem, we thus know, based on the propositions above, that in this economy, if policymaking power is based on majority voting, and if policymaking can use commitment (either for institutional reasons or as the sustainable equilibrium outcome of a dynamic game without commitment between successive median voters), then one should observe output manipulation only at time zero and never again, and the time-zero policy would amount to output stimulation if the median voter is poorer than average (and output taxation if he is richer than average). 


\section{Redistribution without commitment}

We now move to the context where there is no commitment technology and subsidies for period $t$ are chosen at the beginning of period $t$ (still before work decisions have been made). For this environment, we employ the notion of Markov-perfect equilibrium, as used in Krusell and Ríos-Rull (1999). The set of Markov-perfect equilibria is likely large (see the discussion in Krusell and Smith [2003]), and we restrict attention here to Markov-perfect equilibria that would appear as limits of equilibria in the corresponding finite-horizon economies. Thus, we naturally focus on equilibria where equilibrium subsidies are a smooth function of the payoffrelevant state variable. This equilibrium is an interesting benchmark in that it relies only on "fundamentals": by definition, it does not allow any reputational mechanisms.

The payoff-relevant state variable in our economy is whatever feature of the asset distribution matters for the political outcome, and no other feature. Again, given policy, and due to Assumption 1, there is aggregation, and nothing else than mean asset holdings can matter from the economic perspective: in the last period, no other feature matters for outcomes, and thus in the period before the last, no other feature matters either, and so on. ${ }^{7}$ What are the politically relevant features of the asset distribution? The answer depends on the specific political institution being considered. It is useful, as in the section with commitment, to first analyze the problem of an arbitrary non-benevolent policymaker. In such case, the state variable is $a_{i}$ : the asset holdings of the policymaker. From this point on, for simpler notation, we will merely use $a$ to denote his asset holdings.

\subsection{Equilibrium definition based on a simple conjecture}

We will not define a Markov-perfect equilibrium in full generality, since it consumes space, and such a definition would closely follow the definitions in the literature. Instead we will state our conjecture and define an equilibrium based on it.

We conjecture that subsidies in any period are a function of $a: \tau=\Psi(a)$. In other words, $\Psi$ is the fundamental endogenous object we are in search of. Given this conjecture, it should be clear that subsidies, and the asset distribution, will be constant from the beginning of time. Why should this be true? Suppose that, given any function $\Psi$, we (rationally) expect subsidies not to change. Then, $q$ will equal $\beta$, and the asset distribution - in particular, the policymaker asset holdings - will not change. As a result, subsidies next period will indeed be the same, since they are given by the function $\Psi$, evaluated at the policymaker asset level. Thus, the conjecture of a constant subsidy rate is internally consistent. However, could different expectations regarding future subsidies be self-fulfilling? Assuming that $\Psi$ is differentiable, one can show that the answer is negative, at least in the neighborhood of $a=0 .^{8}$

Proceeding with the guess, we compute the policymaker's utility of any next-period asset level as follows:

$$
V(a) \equiv \frac{g(\hat{c}(a), \hat{l}(a))^{1-\sigma}}{(1-\beta)(1-\sigma)}
$$

\footnotetext{
${ }^{7}$ It is conceivable that one can construct a Markov-perfect equilibrium in a political-economy model where other features of the asset distribution matter, even when preferences admit aggregation, but then as a "multiple-equilibrium" phenomenon: other features matter now because they matter in the future. Such equilibria will, however, not be limits of finite-horizon equilibria.

${ }^{8}$ To do this, one can (i) express asset accumulation of the policymaker as a function of current $a$, current subsidies $\Psi(a)$, and future subsidies $\Psi\left(a^{\prime}\right)$, where $a^{\prime}$ is next period's asset holdings, (ii) differentiate the expression, and (iii) evaluate at $a=0$. This delivers a unique linear solution: $a^{\prime}=a$.
} 
where

$$
\hat{c}(a) \equiv\left(1+\frac{a}{e(\Psi(a))}\right) \frac{1-\bar{c}-\bar{l}}{1+z(\Psi(a))}
$$

and

$$
\hat{l}(a) \equiv\left(1+\frac{a}{e(\Psi(a))}\right) \frac{z(\Psi(a))[1-\bar{c}-\bar{l}]}{1+z(\Psi(a))},
$$

where $z(x)$ solves

$$
\frac{g_{2}(1, z)}{g_{1}(1, z)}=1+x
$$

and the function $e$ defining the present-value wealth is calculated given the conjectured constant subsidy sequence:

$$
e(\Psi(a)) \equiv \frac{f(\Psi(a))-\bar{\gamma}(\Psi(a))}{1-\beta},
$$

where $f(\Psi(a))-\bar{\gamma}(\Psi(a))=\frac{[1-\bar{c}-\bar{l}][1+(1+\Psi(a)) z(\Psi(a))]}{1+z(\Psi(a))}$.

We now consider a one-period deviation from the constant-subsidy equilibrium, i.e., the possibility that subsidies in the current period are not necessarily given by $\tau=\Psi(a)$. Now it is useful to define present adjusted consumption and leisure

$$
\tilde{c}\left(a, a^{\prime}, \tau\right) \equiv\left(1+\frac{a}{\tilde{e}\left(a, a^{\prime}, \tau\right)}\right) \frac{1-\bar{c}-\bar{l}}{1+z(\tau)}
$$

and

$$
\tilde{l}\left(a, a^{\prime}, \tau\right) \equiv\left(1+\frac{a}{\tilde{e}\left(a, a^{\prime}, \tau\right)}\right) \frac{z(\tau)[1-\bar{c}-\bar{l}]}{1+z(\tau)},
$$

with

$$
\tilde{e}\left(a, a^{\prime}, \tau\right) \equiv f(\tau)-\bar{\gamma}(\tau)+\tilde{q}\left(a^{\prime}, \tau\right) e\left(\Psi\left(a^{\prime}\right)\right)
$$

and

$$
\tilde{q}\left(a^{\prime}, \tau\right)=\beta\left(\frac{\left[1+z\left(\Psi\left(a^{\prime}\right)\right)\right] g(1, z(\tau))}{[1+z(\tau)] g\left(1, z\left(\Psi\left(a^{\prime}\right)\right)\right)}\right)^{\sigma} \frac{g_{1}\left(1, z\left(\Psi\left(a^{\prime}\right)\right)\right)}{g_{1}(1, z(\tau))},
$$

the current bond price.

Thus, we can define our Markov-perfect equilibrium as follows:

Definition: A Markov-perfect equilibrium is a function $\Psi$ solving

$$
\Psi(a)=\arg \max _{\tau} \frac{\left[g\left(\tilde{c}\left(a, a^{\prime}, \tau\right), \tilde{l}\left(a, a^{\prime}, \tau\right)\right)\right]^{1-\sigma}}{1-\sigma}+\beta V\left(a^{\prime}\right),
$$

where $a^{\prime}$ is given implicitly by the solution to

$$
a^{\prime}=a\left[1-\frac{1}{\tilde{e}\left(a, a^{\prime}, \tau\right)}[f(\tau)-\bar{\gamma}(\tau)]\right] \frac{1}{\tilde{q}\left(a^{\prime}, \tau\right)} .
$$

The latter constraint is the asset accumulation equation, slightly simplified, from Proposition 2 . 


\subsection{Analytical findings and comparisons with the commitment solution}

In this section, we partially characterize the Markov-perfect equilibrium and compare it to the commitment case. In the next section, we continue our analysis using numerical solution techniques.

From now on, we specialize to the case of logarithmic utility.

Assumption 2: Let the instantaneous utility be

$$
u(c, l)=\alpha \ln c+(1-\alpha) \ln l
$$

Under this assumption, the present-value wealth from time endowments, net of taxes, and transfers, under a one-period deviation, is independent of asset holdings. Thus, defining $f(\tau) \equiv \frac{1+\tau}{1+\alpha \tau}$, equation (12) reduces to

$$
\tilde{e}(\tau)=\frac{f(\tau)}{1-\beta},
$$

while the price of bonds becomes

$$
\tilde{q}\left(a^{\prime}, \tau\right)=\beta \frac{f(\tau)}{f\left(\Psi\left(a^{\prime}\right)\right)} .
$$

Consequently, $a^{\prime}$ is implicitly defined by

$$
a^{\prime}=a \frac{f\left(\Psi\left(a^{\prime}\right)\right)}{f(\tau)} .
$$

Equation (13) determines the saving rule for the policymaker, which we denote by $\tilde{h}(a, \tau)$. By replacing the equations above into equations (10) and (11) we obtain expressions for consumption and leisure in the logarithmic case:

$$
\tilde{c}\left(a, a^{\prime}, \tau\right)=\alpha\left[f(\tau)+a-\tilde{q}\left(a^{\prime}, \tau\right) a^{\prime}\right]
$$

and

$$
\tilde{l}\left(a, a^{\prime}, \tau\right)=\frac{(1-\alpha)}{\alpha} \frac{\tilde{c}\left(a, a^{\prime}, \tau\right)}{1+\tau} .
$$

Notice that $\tilde{q}\left(a^{\prime}, \tau\right) a^{\prime}=\beta a$, which implies that we can write

$$
\tilde{c}(a, \tau)=\alpha[f(\tau)+(1-\beta) a] .
$$

The Markov-perfect equilibrium subsidy function $\Psi(a)$ then solves

$$
\max _{a^{\prime}, \tau} \quad \alpha \log \tilde{c}(a, \tau)+(1-\alpha) \log \tilde{l}(a, \tau)+\beta V\left(a^{\prime}\right)
$$

where

$$
V(x) \equiv \frac{1}{1-\beta}\left\{\log \alpha^{2 \alpha-1}(1-\alpha)^{1-\alpha}+\log [f(\Psi(x))+x(1-\beta)]-(1-\alpha) \log [1+\Psi(x)]\right\},
$$


subject to equation (13), i.e., subject to $a^{\prime}=\tilde{h}(a, \tau) \cdot{ }^{9}$ It is clear here how the choice for current subsidies also influences future outcomes through the effect on future subsidies in this model. In particular, $\tau^{\prime}=\Psi\left(a^{\prime}\right)=\Psi(\tilde{h}(a, \tau))$.

Using the assumption that $\Psi$ is differentiable, we can derive a first-order necessary condition. It reads

$$
\begin{gathered}
\frac{1}{1+\tau}-\frac{1}{1+\alpha \tau} \frac{1}{1+\tau+a(1-\beta)(1+\alpha \tau)}+\beta\left\{\frac{a}{(1+\tau)[1+\tau+a(1-\beta)(1+\alpha \tau)]}\right. \\
\left.+\frac{\alpha \Psi\left(a^{\prime}\right)}{(1-\beta)\left(1+\Psi\left(a^{\prime}\right)\right)\left(1+\alpha \Psi\left(a^{\prime}\right)\right)} \Psi_{a}\left(a^{\prime}\right) \tilde{h}_{\tau}(a, \tau)\right\}=0,
\end{gathered}
$$

where $\tilde{h}_{\tau}(a, \tau)$ is given by implicit differentiation of equation (13)..$^{10}$

The first two terms in equation (14) summarize the static trade-off between the net gain from redistribution resulting from a positive subsidy with the negative effect of the introduced distortion in the leisure-labor decision; it is negative at $\tau=0$ if and only if the policymaker is poorer than the mean, $a<0$. This would be the complete analysis in a Meltzer-Richard (static) version of our economy. The remaining part of the first-order condition - the third and fourth terms, which are both of second order at $a=0$ - capture how future utility is affected by a change in current subsidies. The third term incorporates the effects of an induced change in current prices $\left(\tilde{q}\left(a^{\prime}, \tau\right)\right)$ on future consumption and leisure via changes in bond holdings, assuming that the subsidy rate next period remains unaffected (that is, keeping $\Psi\left(a^{\prime}\right)$ constant). The last term describes the indirect effect on utility through how the current subsidy rate alters future subsidy rates.

In a differentiable Markov-perfect equilibrium, condition (14) needs to deliver $\tau=\Psi(a)$; thus $\Psi$ constitutes a fixed point. Moreover, $a^{\prime}$ will equal $a$ in the equilibrium construction. Therefore, we can state a functional equation in $\Psi$ by imposing these conditions in the equations above, resulting - after some simplifications - in the following:

$$
1+\alpha \Psi(a)=\frac{1+\Psi(a)}{1+\Psi(a)+a(1-\beta)(1+\alpha \Psi(a))}+\frac{\alpha \beta \Psi(a)(1+\Psi(a))(1+\alpha \Psi(a))}{(1+\Psi(a))(1+\alpha \Psi(a))-a(1-\alpha) \Psi_{a}(a)} .
$$

This functional equation determines $\Psi$ as a function of $a$ : $\Psi$ has to be such that the equality is met for all values of $a$. The equation can be labeled a "generalized Euler equation", a term also used in other settings with dynamic decisions made without commitment and a Markovperfect equilibrium concept, such as the case with savings under time-inconsistent preferences (see, e.g., Laibson [1997]). In these cases, the first order condition also contains the derivative of the unknown policy function. We will discuss the characterization of $\Psi(a)$ in the context of comparing it to the commitment solution.

\footnotetext{
${ }^{9}$ Here, we use the fact that since consumption can be written as a function of $\tau$ and $a$ only, $\tilde{l}(a, \tau)=$ $\frac{(1-\alpha)}{\alpha} \frac{\tilde{c}(a, \tau)}{1+\tau}$.

${ }^{10}$ The derivation of equation (14) involves an intermediate step where we substitute equation (13), where $x=a \frac{f(\Psi(x))}{f(\tau)}$, and use the properties of logarithmic functions to separate the direct effects of $\tau$ on $V(x)$ from those resulting from indirect changes through $\Psi(x)$. Using $a^{\prime}$ as shorthand for $\tilde{h}(a, \tau)$,
} implicit differentiation of (13) delivers

$$
\tilde{h}_{\tau}(a, \tau)=\frac{a \alpha\left(1+\Psi\left(a^{\prime}\right)\right)-a^{\prime}\left(1+\alpha \Psi\left(a^{\prime}\right)\right)}{(1+\tau)\left(1+\alpha \Psi\left(a^{\prime}\right)\right)+\left(\alpha a^{\prime}(1+\tau)-a(1+\alpha \tau)\right) \Psi_{a}\left(a^{\prime}\right)} .
$$


Under time-zero voting, we can directly apply the insights from Section 3. However, it is useful to take one step back and restate the commitment problem here, because this allows for a convenient parallel to the problem without commitment. The problem can be stated

$$
\max _{\left\{\tau_{t}, a_{t+1}\right\}_{t=0}^{\infty}} \sum_{t=0}^{\infty} \beta^{t}\left[\log \left(f\left(\tau_{t}\right)+a_{t}-\beta \frac{f\left(\tau_{t}\right)}{f\left(\tau_{t+1}\right)} a_{t+1}\right)-(1-\alpha) \log \left(1+\tau_{t}\right)\right] .
$$

This problem is unconstrained: one can easily show that the choice for asset holdings delivers

$$
a_{t+1}=a_{t} \frac{f\left(\tau_{t+1}\right)}{f\left(\tau_{t}\right)}
$$

which would have been the constraint representing equilibrium choices (thus, maximization over a larger choice set leads to a choice within the restricted set, so the restriction can be ignored).

Knowing that subsidies from period 1 and on are constant, and that this implies that bond holdings are also constant from period 1 on, we obtain, for all $a$, that subsidies in period zero satisfy

$$
\frac{1}{1+\tau_{0}}-\frac{1}{1+\alpha \tau_{0}} \frac{1}{1+\tau_{0}+a(1-\beta)(1+\alpha \tau)}+\beta \frac{a}{\left(1+\tau_{0}\right)\left[1+\tau_{0}+a(1-\beta)\left(1+\alpha \tau_{0}\right)\right]}=0,
$$

where $a$ now refers to $a_{0}$, for ease of comparison with the no-commitment solution. That is, $\tau_{0}$ denotes the first-period choice for subsidies under commitment. Slightly abusing notation, we denote the subsidy function that solves the equation above by $\tau_{0}(a)$.

Comparing equations (14) and (16) we see only one difference: the former - the no-commitment case - has an extra term. The reason is that under a period-by-period voting mechanism, the current policymaker does not have a direct control over future subsidies: it can only affect them indirectly via the level of $a^{\prime}$. If the policy function were constant, i.e., if it did not depend on $a$, so that $\Psi_{a}(a)=0$ in the expression above, then the commitment solution would be time-consistent. However, we know that it cannot be, because the commitment solution does deliver a subsidy rate that depends on $a$ : simple inspection of equation (16) reveals that $\tau_{0}(a)$ cannot be independent of $a$. Thus, in general, $\Psi(a) \neq \tau_{0}(a)$. We see, however, that for $a=0$, so long as $\Psi(a)$ is differentiable at 0 , both equations (14) and (16) deliver zero subsidies: $\Psi(0)=\tau_{0}(0)=0$. That is, if the policymaker's asset holdings equal the mean, then subsidies are zero, no matter how voting takes place. The agent chooses not to distort labor decisions because he cannot redistribute resources in his favor. Since his asset holdings do not change (he chooses to hold no debt), subsidies in the future will also be zero under commitment. There are no incentives to deviate from this policy once period one arises, and thus the policy is time-consistent.

It is also possible to compare the cases with and without commitment in the neighborhood of equality of the policymaker's income and mean income $(a=0)$. First, note that initial subsidies under commitment allow for a closed-form solution, and that the implied slope of $\tau_{0}(a)$ can be determined. ${ }^{11}$ Thus, it follows in particular that the slope of $\tau_{0}(a)$ at the origin

\footnotetext{
${ }^{11}$ One obtains a second-order polynomial expression for $\tau_{0}$ for each $a$, yielding$$
\tau_{0}^{*}=\frac{\alpha\left[-1+a_{0}(\beta-2)\right]+\sqrt{\alpha^{2}\left[-1+a_{0}(\beta-2)\right]^{2}-4 a_{0} \alpha\left(1+a_{0} \alpha(1-\beta)\right)}}{2 \alpha\left(1+a_{0} \alpha(1-\beta)\right)} .
$$ 
is given by

$$
\left.\frac{d \tau_{0}}{d a_{0}}\right|_{a_{0}=0}=-\frac{1}{\alpha},
$$

i.e., that at least locally around the point where the policymaker has mean income, initial subsidies are decreasing at the rate $1 / \alpha>1$ in the policymaker's asset holdings. Thus, the higher is the preference weight on consumption relative to leisure $(\alpha)$, the less do subsidies respond to inequality between mean income and that of the agent choosing policy. Intuitively, a low relative value of leisure makes the labor effort differ less across wealth groups, so for each $a$ there is a smaller labor income discrepancy across groups and, hence, lower benefits from redistribution.

Interestingly, around the point where the policymaker's wealth equals mean wealth, the local (first-order) sensitivity of first-period subsidies to inequality is the same under sequential voting as under time-zero voting, provided that $\Psi$ is twice differentiable at zero. Showing this, i.e., that $\Psi_{a}(0)=-1 / \alpha$, is straightforward: it amounts to differentiating equation (15) with respect to $a$, then evaluating the resulting expression at $a=0$, and verifying that $\Psi_{a}=-1 / \alpha$ solves the equation. ${ }^{12}$

Furthermore, it is possible to see that, in the neighborhood of $a=0$ but for strictly negative values of $a$, subsidies under the no-commitment case are higher than under commitment, i.e., that

$$
\Psi(a)>\tau_{0}(a) .
$$

This can be seen as follows. For a small negative level of debt, the fourth term of equation (14) is negative since (i) the terms in parenthesis in the denominator are positive, because the policymaker subsidizes when $a<0$; (ii) $\Psi_{a}(a)<0$ at zero; and (iii) $\frac{d \tau^{\prime}}{d \tau}=\Psi_{a}(a) \tilde{h}_{\tau}(a, \tau)<0$, which can be shown by using the fact that $\Psi(a)$ is decreasing in this neighborhood. Given this, at the commitment level of subsidization, the first line is zero while the second one is negative; hence, the equality in equation (14) cannot hold. The policymaker must then adjust $\tau$ by increasing the first term. This can only be done by increasing $\tau$, since the first term is increasing in $\tau$ for small as. These differences will be illustrated numerically in the next section. The reason why subsidies are higher in the first period when there is no commitment comes from the fact that interest-rate manipulation is actually easier when there is no commitment due to a feedback effect. To see why, from equation (13), a raised subsidy today will make the policymaker's asset holding come closer to zero: first, it will lower $a^{\prime} / a$ since it raises consumption today directly and hence lowers the interest rate; second, since $a^{\prime} / a$ tends to fall, there is a feedback through the lower implied subsidy rate tomorrow, further lowering the interest rate. Thus, the feedback effect of lower future subsidies coming from a raised subsidy today, which is not present under commitment because future subsidies are always zero in that case, increases the interest-rate effect of a given subsidy change when there is a lack of commitment.

\subsection{A numerical example and a computational challenge}

We proceed using the case of logarithmic utility. Using the method described in Krusell, Kuruşçu, and Smith (2002), we solve the model numerically using the parameter values $\alpha=0.3$

\footnotetext{
${ }^{12}$ The expression involves the product of the second derivative of the policy rule, $\Psi_{a a}(a)$, and the level of assets $a$. The term cancels out at $a=0$ under the assumption that $\left|\Psi_{a a}(a)\right|<\infty$.
} 
and $\beta=0.9 .^{13}$ It delivers the following results in a neighborhood of $a=0$. Figure 1 illustrates

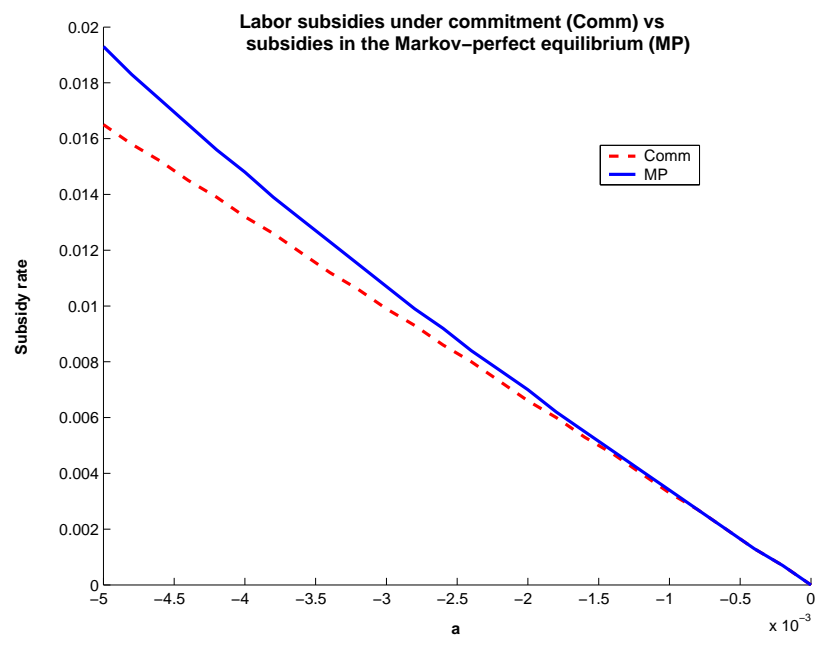

Figure 1: Numerical solution of the model under logarithmic utility

the features derived in the previous section: the commitment and Markov-perfect solutions that coincide at zero asset holdings of the policymaker have the same slope at that point, with the commitment solution giving lower subsidies for strictly negative values of policymaker's assets.

It turns out that the model here presents a formidable computational problem. Figure 1 displays the subsidy function in a very small neighborhood around zero asset holdings. It is, however, very difficult to extend the results beyond this small neighborhood, and we contend that it is an open problem how to best approximate equilibria in cases like this one. As an illustration, we include numerically computed first-period policy rules (policymaker's asset accumulation and the chosen subsidy rate) for a sequence of economies with an increasing time horizon: we look at horizons of length 1 through 9 . These decision rules are solved by discretizing the space of asset holdings, using a very fine grid. Figures 2 and 3 report the results.

As can be seen, first, in Figure 2, assets move toward zero, since the model has a finite horizon; for longer time horizons, the asset rule is closer to the 45-degree line, as expected (in the infinite-horizon Markov-perfect equilibrium, assets are constant over time, i.e., the decision rule is the 45-degree line).

In Figure 3 we see the decision rules for subsidies. As expected, the subsidy function is negatively sloped, goes through zero, and is higher, the longer the time horizon: the future benefits of redistribution engineered by raising $q$ in the first period are higher, the longer the future period over which the higher asset holdings are used. However, what is probably more eye-catching in the figure is the fact that wiggles appear in the subsidy function at longer horizons. We have not been able to find ways of making sure that no wiggles appear. The numerical problems may be related to the fact that one expects the equilibrium subsidy rate to approach $\infty$ as the policymaker's asset holdings approach its lowest feasible value. For the infinite-horizon model, this value, $\underline{a}$, solves $1+\frac{a}{E(\infty)}=0$; for logarithmic utility, $\underline{a}=-\frac{1}{\alpha(1-\beta)}$.

\footnotetext{
${ }^{13}$ We have also used a pure grid method, based on the definition of the equilibrium involving value functions. It reproduces these results.
} 


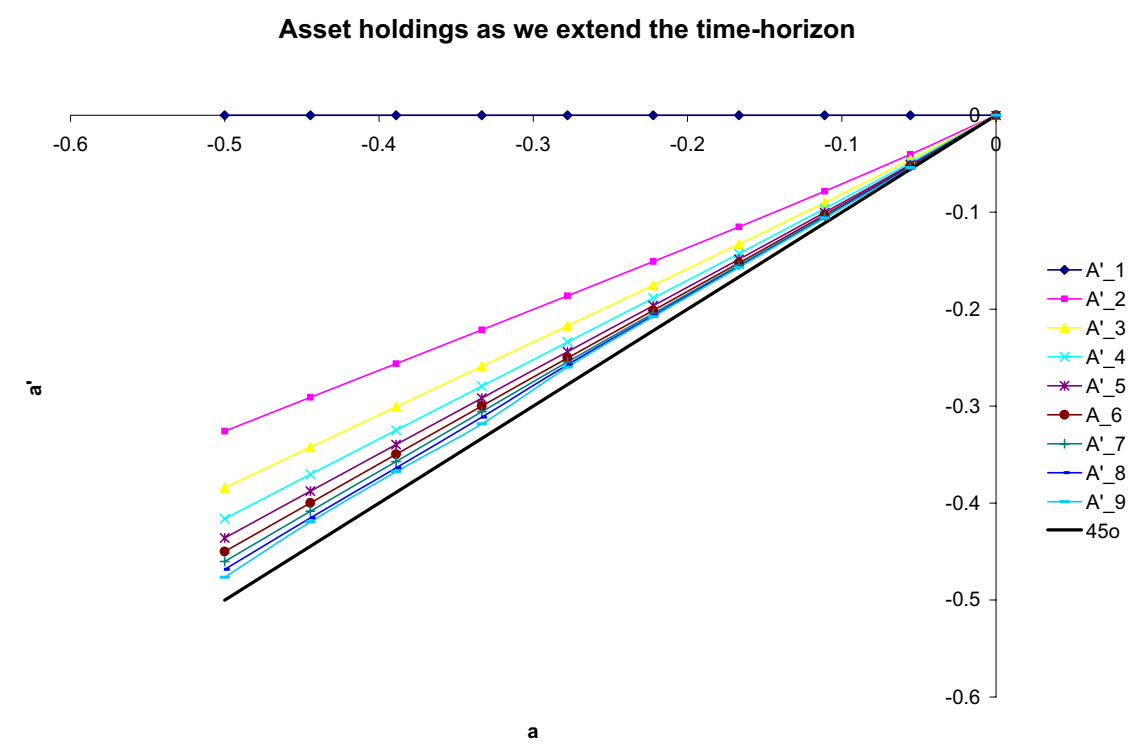

Figure 2: Next-period assets in the first period for a sequence of finite-horizon economies

Numerical instability of Markov-perfect equilibria has been noted before, beginning in Krusell and Smith (2003). The idea there, loosely speaking, is that wiggles/numerical errors, once they appear, tend to reproduce and amplify due to the time-inconsistency inherent in the decision problem. This delivers a non-concave objective function and, eventually, discontinuous behavior.

\section{Conclusions}

With this paper, we continue the exploration of dynamic macroeconomic models of endogenous policy choice. We focus on a case where the only source of disagreement on policy is the heterogeneity of initial asset positions. Initially well-endowed consumers choose to work less, and a poor median voter thus wants to subsidize labor, right. The case is interesting and nontrivial also because interest rates are endogenous and call for manipulation by the median voter: they are adjusted so as to change his net-present-value wealth position, in effect, by lowering the interest rate so that the debt he carries is an easier burden.

The sequence of subsidies chosen by the policymaker (or median voter) under commitment involves zero subsidies from period 1 and on, presuming that preferences are in a class admitting aggregation. We ensure that a median-voter theorem obtains under the same conditions. The choice of subsidies is not time-consistent, however: without commitment, subsidies will be constant (and non-zero) over time. Asset inequality changes between the first two periods in the case with commitment - inequality is reduced - but under lack of commitment, there is no 


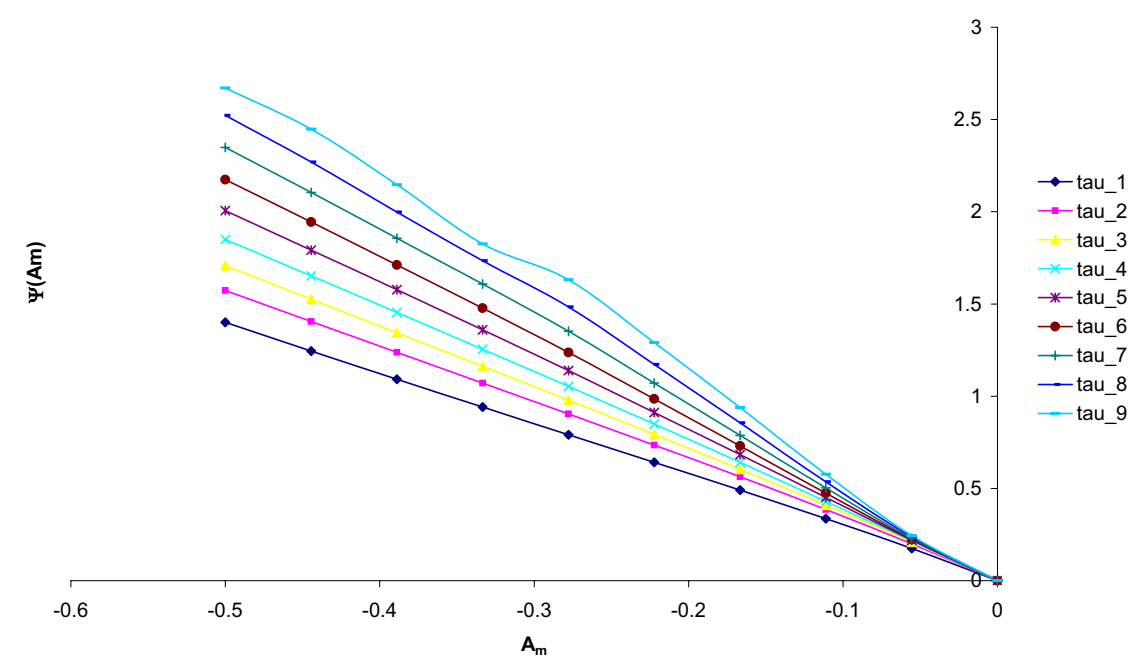

Figure 3: Subsidies in the first period for a sequence of finite-horizon economies

change in asset inequality, despite the power of the median voter to subsidize labor income.

Open issues remain, particularly regarding the characterization of Markov-perfect equilibria. Even though we show that the present model, like the model of savings under quasigeometric preferences, reduces to a simple-to-express functional equation - equation (15), which has one unknown function of one variable - it is surprisingly difficult to characterize equilibrium globally, even numerically. It is therefore an outstanding challenge to search for numerical methods aiding the analysis of Markov-perfect equilibria in this and similar kinds of models. 


\section{Appendix}

\subsection{Proof of Lemma 1}

We have that

$$
E(\tau)=\sum_{t=0}^{\infty} \prod_{k=0}^{t} q_{k-1}\left\{f_{t}-\bar{\gamma}_{t}\right\}
$$

and that

$$
q_{t}=\beta\left(\frac{1+z_{t+1}}{1+z_{t}}\right)^{\sigma} \frac{1}{\epsilon_{t}}
$$

$\epsilon_{t}=\frac{g_{1}\left(1, z_{t}\right)}{g_{1}\left(1, z_{t+1}\right)}\left[\frac{g\left(1, z_{t+1}\right)}{g\left(1, z_{t}\right)}\right]^{\sigma}$. It follows that the discount factor $\prod_{k=0}^{t} q_{k-1}$ equals

$$
\begin{gathered}
\beta\left[\frac{\left(1+z_{1}\right) g\left(1, z_{0}\right)}{\left(1+z_{0}\right) g\left(1, z_{1}\right)}\right]^{\sigma} \frac{g_{1}\left(1, z_{1}\right)}{g_{1}\left(1, z_{0}\right)} \times \beta\left[\frac{\left(1+z_{2}\right) g\left(1, z_{1}\right)}{\left(1+z_{1}\right) g\left(1, z_{2}\right)}\right]^{\sigma} \frac{g_{1}\left(1, z_{2}\right)}{g_{1}\left(1, z_{1}\right)} \times \ldots \\
\times \beta\left[\frac{\left(1+z_{t}\right) g\left(1, z_{t-1}\right)}{\left(1+z_{t-1}\right) g\left(1, z_{t}\right)}\right]^{\sigma} \frac{g_{1}\left(1, z_{t}\right)}{g_{1}\left(1, z_{t-1}\right)} .
\end{gathered}
$$

This can be simplified to

$$
\prod_{k=0}^{t} q_{k-1}=\beta^{t}\left[\frac{\left(1+z_{t}\right) g\left(1, z_{0}\right)}{\left(1+z_{0}\right) g\left(1, z_{t}\right)}\right]^{\sigma} \frac{g_{1}\left(1, z_{t}\right)}{g_{1}\left(1, z_{0}\right)} .
$$

Inserting this expression back into equation (17), we obtain

$$
E(\tau)=\sum_{t=0}^{\infty} \beta^{t}\left[\frac{\left(1+z_{t}\right) g\left(1, z_{0}\right)}{\left(1+z_{0}\right) g\left(1, z_{t}\right)}\right]^{\sigma} \frac{g_{1}\left(1, z_{t}\right)}{g_{1}\left(1, z_{0}\right)}\left\{f_{t}-\bar{\gamma}_{t}\right\}
$$

We know that $\frac{1+z_{t}}{1+z_{0}}=\frac{\hat{C}_{0}}{\hat{C}_{t}}$. With the definition of $f_{t}$ and the functional form for average consumption, it is possible to show that $f_{t}-\bar{\gamma}_{t}=\hat{C}_{t}\left[1+\left(1+\tau_{t}\right) z_{t}\right]$. Using these two equalities, we can write

$$
E(\tau)=\sum_{t=0}^{\infty} \beta^{t}\left[\hat{C}_{t} g\left(1, z_{t}\right)\right]^{1-\sigma} \frac{\left[1+\left(1+\tau_{t}\right) z_{t}\right] g_{1}\left(1, z_{t}\right)}{g\left(1, z_{t}\right)} \frac{\left[\hat{C}_{0} g\left(1, z_{0}\right)\right]^{\sigma}}{g_{1}\left(1, z_{0}\right)}
$$

Let $\Omega\left(\tau_{0}\right) \equiv(1-\sigma)\left[\hat{C}_{0} g\left(1, z_{0}\right)\right]^{\sigma} g_{1}\left(1, z_{0}\right)^{-1}=(1-\sigma)\left[g\left(\hat{C}_{0}, \hat{L}_{0}\right)\right]^{\sigma} g_{1}\left(\hat{C}_{0}, \hat{L}_{0}\right)^{-1}$, where the second equality follows from the homogeneity of $g$. Using equation 1 , we can write

$$
1+\left(1+\tau_{t}\right) z_{t}=\frac{g_{1}\left(1, z_{t}\right)+g_{2}\left(1, z_{t}\right) z_{t}}{g_{1}\left(1, z_{t}\right)}=\frac{g\left(1, z_{t}\right)}{g_{1}\left(1, z_{t}\right)}
$$

where the first equality follows from the optimality condition of agents in their consumptionleisure choice, and the second equality holds due to the Euler theorem for homogeneous functions. With this, $E(\tau)$ reduces to

$$
E(\tau)=\Omega\left(\tau_{0}\right) \underbrace{\sum_{t=0}^{\infty} \beta^{t} \frac{\left[g\left(\hat{C}_{t}, \hat{L}_{t}\right)\right]^{1-\sigma}}{1-\sigma}}_{=V_{0}(\tau)} .
$$




\subsection{Proof of Proposition 4}

As a first step it is useful to characterize the optimal sequence of subsidies preferred by the representative agent. They must satisfy

$$
\frac{\partial V_{0}}{\partial \tau_{t}}=g\left(\hat{C}_{t}, \hat{L}_{t}\right)^{-\sigma} \frac{[1-\bar{c}-\bar{l}]}{\left(1+z_{t}\right)^{2}} \frac{d h_{t}}{d \tau_{t}}\left[g_{1}\left(1, z_{t}\right)-g_{2}\left(1, z_{t}\right)\right]=0 \quad \forall t
$$

Therefore, an agent with average wealth would choose a policy that delivers $g_{1}\left(1, z_{t}\right)=g_{2}\left(1, z_{t}\right)$ in equilibrium. From the optimality condition equation (1), it implies that this agent prefers $\tau_{t}=0 \forall t$ to any other sequence, so that the marginal utilities of consumption and leisure are the same. Intuitively, this agent obtains no net redistribution (the subsidies paid amount to the transfers received) and does not benefit from changing interest rates, since she has no assets. There is no gain from taxing or subsidizing labor, but a second-order loss generated by the distortion it generates on labor decisions. As a result, she finds it optimal to set subsidies equal to zero. The median agent on the other hand, can gain from net redistributions and the manipulation of the interest rate sequence.

The indirect time-zero utility function of an agent with wealth $a_{i 0}$ can be written as a function of the mean agent's utility and the rate at time 0 , as we have shown above. That is,

$$
V_{i 0}(\tau)=\left[1+\frac{a_{i 0}}{\Omega\left(\tau_{0}\right) V_{0}(\tau)}\right]^{1-\sigma} V_{0}(\tau)
$$

The first-order condition with respect to subsidies at time $t \geq 1$ is

$$
\frac{\partial V_{i 0}}{\partial \tau_{t}}=\lambda_{i}(\tau)^{1-\sigma}\left[1-\frac{(1-\sigma) a_{i}}{\Omega\left(\tau_{0}\right) V_{0}(\tau) \lambda_{i}(\tau)}\right] \frac{\partial V_{0}(\tau)}{\partial \tau_{t}}=0
$$

so the median will choose $\tau_{t}=0$ for any $t \geq 1$.

We need to make sure that this is indeed a maximum. The second-order condition evaluated at the optimum is

$$
\frac{\partial^{2} V_{i 0}}{\partial \tau_{t}^{2}}=\lambda^{1-\sigma}\left[1-\frac{(1-\sigma) a_{i}}{\Omega\left(\tau_{0}\right) V_{0}(\tau) \lambda_{i}(\tau)}\right] \frac{\partial^{2} V_{0}(\tau)}{\partial \tau_{t}^{2}}
$$

Then $\frac{\partial^{2} V_{i 0}}{\partial \tau_{t}^{2}}<0$ if and only if the term in brackets is positive. The latter will hold as long as the agent's initial asset holdings satisfy

$$
a_{i 0}>-\frac{\Omega\left(\tau_{0}\right) V_{0}(\tau)}{\sigma} .
$$

If $\sigma \leq 1$, this condition is met. In order for the competitive equilibrium allocations to be well defined we need the i's share of income $\lambda_{i} \geq 0$. But that translates exactly to the condition $a_{i 0}>-\Omega\left(\tau_{0}\right) V(\tau)$. Thus, this condition is met whenever $\sigma \leq 1$.

On the other hand, when $\sigma>1$ the condition is not automatically satisfied. In this case, the second-order conditions might be violated if $a_{i 0}$ is too low, which imposes a restriction on the degree of initial inequality for which a zero-tax policy will be chosen in equilibrium. 


\section{References}

[1] Aiyagari, S. R. (1994), Uninsured idiosyncratic risk and aggregate savings, Quarterly Journal of Economics, 659-684.

[2] Atkinson, A.A. (1971), Capital Taxes, the Redistribution of Wealth and Individual Savings. AB Atkinson, Review of Economic Studies, 38:2, 209-227.

[3] Altig, D., A. Auerbach, L. Kotlikoff, K. Smetters, and Walliser, J. (2001), Simulating Tax Reform in the United States, American Economic Review, June, 91:3.

[4] Azzimonti, M., de Francisco, E. and Krusell, P. (2006) Median-Voter Equilibria in the Neoclassical Growth Model Under Aggregation. Manuscript.

[5] Bassetto, M. and Benhabib, J. (2006), Redistribution, Taxes and the Median Voter, Review of Economic Dynamics, 9:2, 211-223.

[6] Chamley, C. (1986), Optimal Taxation of Capital Income in General Equilibrium with Infinite Lives, Econometrica, 54, 607-22.

[7] Correia, I. (1999a) On the Efficiency-Equity Trade-Off, Journal of Monetary Economics, 44, 581-603.

[8] Correia, I. (1999b) Fiscal rules of Income Transformation, Economic Theory, 13:1, 199205.

[9] Garcia-Milà, T., Marcet, A. and Ventura, E. (2001), Supply Side Interventions and Redistribution, Economics Working Papers 115, Department of Economics and Business, Universitat Pompeu Fabra.

[10] Greenwood, J., Hercowitz, Z., and Huffman, G., (1988), Investment, capacity utilization, and the real business cycle, American Economic Review, 78, 402-417.

[11] Huggett, M. (1993), The Risk-Free Rate in Heterogeneous-Agent Incomplete-Insurance Economies, Journal of Economic Dynamics and Control, 17, 953-969.

[12] Judd, K. (1985), Redistributive Taxation in a Simple Perfect Foresight Model, Journal of Public Economics, 28, 59-83.

[13] Klein, P., Krusell, P. and Ríos-Rull, J.V., 2005, Time-Consistent Public Expenditures, Working Paper.

[14] Krusell, P. and Smith, A. (1998), Income and Wealth Heterogeneity in the Macroeconomy, Journal of Political Economy, 106, 867-896.

[15] Krusell, P., Kuruş̧̧u B., and Smith, A. (2002), Equilibrium Welfare and Government Policy with Quasi-Geometric Discounting, Journal of Economic Theory, 75, 42-72.

[16] Krusell, P. and Ríos-Rull, J.V. (1999), On the Size of Government: Political Economy in the Neoclassical Growth Model, American Economic Review, 89:5, 1156-1181.

[17] Krusell, P. and Smith, A. (2003), Consumption-Savings Decisions with Quasi-Geometric Discounting, Econometrica, 71, 365-375. 
[18] Krusell, P. and Smith, A. (2006), Quantitative Macroeconomic Models with Heterogeneous Agents, in Blundell, R., Newey, W., and Persson, T. (eds), Advances in Economics and Econometrics: Theory and Applications, Ninth World Congress, Cambridge University Press.

[19] Laibson, D. (1997), Golden Eggs and Hyperbolic Discounting, Quarterly Journal of Economics, 112:2, 443-77.

[20] Maskin, E. and Tirole, J. (2001), Markov Perfect Equilibrium, Journal of Economic Theory, 100:2, 191-219.

[21] Meltzer, A.H. and Richard, S.F., 1981, A Rational Theory of the Size of Government, Journal of Political Economy, 89:5, 914-27.

[22] Lucas, R. and Stokey, N. (1983), Optimal Fiscal and Monetary Policy in an Economy Without Capital, Journal of Monetary Economics, 12:1, 55-93.

[23] Roberts, K. (1977), Voting over income tax schedules, Journal of Public Economics, 8:3, 329-340. 